\title{
Research and Planning of Application Blueprint for Shanghai Airport Business Intelligence System
}

\author{
Huigang Fu \\ Business School, University of Shanghai for Science and Technology \\ Shanghai 200093, China \\ E-mail: fuhuiganghappy@163.com \\ Chongjun Fan (Corresponding author) \\ Business School, University of Shanghai for Science and Technology
}

Shanghai 200093, China

Tel: 86-138-0171-5020Ｅ-mail: cjfan@sh163.net

Jianbai Wang

Business School, University of Shanghai for Science and Technology

Shanghai 200093, China

E-mail: wangjianbai@hotmail.com

Ding Fang

IT Dept., Shanghai Airport Authority

Shanghai 200335, China

$\mathrm{Lu} \mathrm{Yu}$

IT Dept., Shanghai Airport Authority

Shanghai 200335, China

Xianglai Ran

IT Dept., Shanghai Airport Authority

Shanghai 200335, China

Received: November 11, 2011

Accepted: November 28, 2011

Published: January 1, 2012

doi:10.5539/cis.v5n1p32

URL: http://dx.doi.org/10.5539/cis.v5n1p32

The research is financed by the research project of Shanghai Airport Authority. (Sponsoring information).

\begin{abstract}
The strategic goal of Shanghai Airport is to build a perfect domestic and international route network, and construct the air gateway connecting the world with China. Shanghai Airport is speeding up the construction of information systems, and business intelligence is core of the airport decision support system. First, this paper discusses the application blueprint of business intelligence for Shanghai Airport. Second, it analyses and designs the technical architecture of Shanghai Airport business intelligence system. Finally, it explores the application architecture of Shanghai Airport business intelligence system and the key functions of the modules. This paper aims to provide reference and help for the research and planning of related airport projects.
\end{abstract}

Keywords: Business intelligence, Application blueprint, Data warehouse, Data mining, Airport 


\section{Introduction}

The total volume of the world air transportation industry is continuing growing rapidly. With the air transportation industry gradually open, hub of the airline structure and alliance of operation, Shanghai Airport has developed a strategic goal that it is to build a perfect domestic and international route network and the core hub of the Asia-Pacific region, construct the air gateway connecting the world with China, and eventually make Shanghai Airport into a major world airline network node by striving after a few years (Wu, 2010).

As Shanghai Airport manages Pudong Airport and Hongqiao Airport, the overall goal of business intelligence system must be closely going around the Shanghai Airport's strategy in order to promote the change management by technological progress, lower cost and risk, improve management, increase efficiency and effectiveness, and eventually enhance the core competence of Shanghai Airport (Fan, Xiong, Zhang, \& Liu, 2010). As the enterprise scale is constantly expanding, and the throughput of passengers and cargoes is rising gradually, business intelligence is essential. Business intelligence has become the fundamental guarantee that Shanghai Airport participates in the competition and maintains a rapid development.

With the visualization of performance measurement tools and real-time analysis methods, business intelligence comprehensively and accurately reflects the operating status of the entire enterprise and the level of performance. With the core technology of business intelligence, it is more intelligent than ever for enterprise in whether data utilization, analysis and decision-making, or process optimization and performance management.

The applications of business intelligence in the airports are currently the SAP-SEM implemented in Beijing Airport and the IBM-Cognos implemented in Hong Kong Airport (Zhang et al., 2011). As Shanghai Airport manages Pudong Airport and Hongqiao Airport, this paper discusses the application blueprint of Shanghai Airport business intelligence, and explores the technical architecture and the application architecture of Shanghai Airport business intelligence system and the key functions of the modules based on the management model of Shanghai Airport Authority.

\section{Technical Architecture of Shanghai Airport Business Intelligence System}

The comprehensive construction of Shanghai Airport business intelligence system can be divided into operation information systems and management information systems. Operation information systems mainly involve the aircrafts from take-off to landing and the passengers from starting to arriving, such as integration, departure, baggage, flight display, public addressing and so on. Management information systems use advanced information technology to manage humans, finances and materials of the enterprise, such as financial management, equipment management, human resource management, business intelligence and so on (Fang, 2010). The application blueprint of Shanghai Airport business intelligence system is shown in Figure 1.

Manufacturing operation layer supporting the flight operation is divided into flight information related systems, security monitoring related systems and equipment and facility management related systems. Flight information related systems covering three aspects are divided into flight information systems, passenger service systems, and integrated management systems. Flight information systems include airport operation database, flight information management system, resource management system, interface message broker, flight query system, network, and flight control system. Passenger service systems include departure control system, flight information display system, public addressing, and call center (Xiong et al., 2010). Integrated management systems include airport management database, airline billing system, airline business statistics system, and passenger and baggage information system (Xiong, Fan, Liu, \& Zhang, 2010). Security monitoring related systems includes closed circuit television, access control system, flight area prevention system, and fire control system. Equipment and facility management related systems include elevator monitoring, boarding bridge management system, airfield light control, building automation system, parking management, airplane-parking guidance system, community antenna television, clock, $35 \mathrm{kv}$ power monitoring, road monitoring, and water supply and drainage control system (Zhang et al., 2010).

Management support layer includes purchasing inventory management system, property lease management system, asset management system, contract management system, tender management system, human resource management system, investment project management system, customer relationship management system, and financial management system.

The construction of business intelligence in the decision support layer is based on that operation information systems and management information systems are fully completed and operated for some time, and accumulate a large number of business and management data. Meanwhile, the interface message broker provides a bridge for information exchange and data format transformation, and solves the problem of data acquisition in the 
construction of business intelligence.

The operating management model of Shanghai Airport Authority is "two airports in a city, Pudong Airport based, Hongqiao Airport assisted". Therefore, the construction of business intelligence system must combine the model (Fan, 2004). According to the Shanghai Airport Authority application deployment model, business intelligence system belongs to authority standard systems whose standards are set by the Authority and which are implemented by Pudong Airport and Hongqiao Airport according to the respective operation and management situation.

The business of Shanghai Airport mainly involves flight operation business and non-flight operation business. Flight operation business includes aircrafts from takeoff to landing and passengers from starting to departure. Non-flight operation business includes logistics management, airport commercial management, and lease management. The revenue growth of non-flight operation business is currently faster than that of flight operation business. Based on the characteristics of Shanghai Airport business and management and the trends of business intelligence, this paper proposes the technical architecture of Shanghai Airport business intelligence system. It is shown in Figure 2.

The technical architecture of Shanghai Airport business intelligence system consists of four parts. They are data acquisition, data management, data analysis, and data display.

Data acquisition is the basis of the entire data warehouse and business intelligence. The data includes internal information and external information. Internal information primarily gets data from systems through interface message broker. Those systems are airport management database, contract management system, tender management system, resource management system, customer relationship management system, human resource management system, and financial management system. External information primarily gets data from internet, industry journals, and competitors. Those data can be structured, and also can be unstructured.

Data management includes ETL (Extract Transformation Load), data warehouse and data marts. It is a building process of data warehouse. In the building of data warehouse, the process of ETL bears the largest workload and produces the most problems in the daily operation. ETL includes data extraction, data transformation, data cleaning and data loading. While data warehouse is built, the data marts are established, such as finance mart, human mart, customer mart, production mart and so on.

Data analysis includes OLAP (On-Line Analytical Processing) server, data mining models and report styles. OLAP server enables analysts, managers, and executives rapidly, consistently, and interactively analyze data from multi-angle and multi-level. Data mining models are to extract the information and knowledge previously unknown and potentially useful from masses of data, such as customer classification model, business analysis and prediction models. Report styles mainly provide the required report styles for the Civil Aviation Administration of China, the State-owned Asserts Supervision and Administration Commission of the State Council, and senior leaders, and additionally supply the freely-designed report kits.

Data display includes report, OLAP, ad-hoc query, and data mining. Report transforms the data of data warehouse into reports highly formatted, easily understood, and diversified professional. These reports can help senior managers make quick and accurate decisions. OLAP helps the user quickly and easily analyze large amounts of data from multiple angles. Ad-hoc query can help users produce statistical reports according to their needs and choices, and flexible options. Data mining can transform data into useful information very well, such as analysis of the relationships and trends between flight income and business income, analysis of the relationships between operation income and cost, and mining the potential customers.

\section{Application Architecture of Shanghai Airport Business Intelligence System}

Based on the demand analysis of senior managers in the airports and relevant departments, and paper queries, this paper proposes the application architecture of Shanghai Airport business intelligence system. It is shown in Figure 3.

Information delivery management is the airport platform for internal information delivery, including news, announcements (meeting notices, training, notification, holiday notices).

Decision support information management primarily orients to the applications for senior airport managers (mainly the senior authority leaders, taking Pudong Airport and Hongqiao Airport into account). The main role of the module is to supply the senior airport managers with reports and information so that senior managers can scientifically manage and make decisions.

Market analysis management supplies marketing department with market analysis on flight business, non-flight 
business, commercial retail, airlines, VIP companies, passenger terminal merchants, and freight, and reports.

Statistical information management supplies statistical department with statistical analysis of monthly operating reports, three-year plan, annual statistical yearbook, project progress of the Authority and subsidiaries, housing asset analysis, operating risk analysis (Fan et al., 2009), and energy analysis.

Financial information management supplies financial department with key business information, reports, and simple data analysis tools oriented to financial decision-making.

Human resource information supplies the senior airport managers with basic information of employees in the key positions, particularly real-time information of the middle and senior managers, so that airport managers can facilitate the deployment of senior personnel through departments and entities.

Key business information mainly provides in-depth analysis of operating income and cost, cost structure analysis of flight business, revenue analysis of flight income and non-flight income, analysis of passenger satisfaction and passenger congestion and evacuation, and emergency management analysis.

Data mining mainly provides environment and tools for the building of data analysis models, such as customer classification model, dynamic analysis and forecasting model of business data, decision optimization model and so on.

Key business system link mainly provides some links of the key systems, including the systems having the characteristic of business intelligence and supplying users with business operating situation.

System management includes data loading, data backup and right management.

\section{Conclusions}

As Shanghai Airport manages Pudong Airport and Hongqiao Airport, business intelligence is essential to decision-making of business and management. This paper discusses the application blueprint of business intelligence for Shanghai Airport, and explores the technical architecture and the application architecture of Shanghai airport business intelligence system and the key functions of the modules. This paper can provide the reference and help for the research of related airport projects.

\section{Acknowledgements}

This research was supported by the research project of Shanghai Airport Authority. Expresses the thanks.

\section{References}

Fan, Chongjun. (2004). Strategically Programming of Information Technology under Group Management Mode. Construction Machinery and Equipment, 35(9), 34-37.

Fan, Chongjun, Xiong, Honglin, Zhang, Haiying, \& Liu, Wujun. (2010). Risk Management Approach of Hongqiao Airport Informationization Construction Project. Science and Technology Management Research, 30(8), 129-132.

Fan, Chongjun, Xiong, Honglin, Zhang, Haiying, Liu, Wujun, Wang, Liqiang, \& Song, Xiaohui. (2009). Analysis of network security and risks prevention strategies of Hongqiao Airport West Terminal. Computer and Information Science, 2(3), 46-52.

Fang, Ding. (2010). Pudong Airport management information system oriented to strategy. Shanghai Airport, 11, 82-89.

Wu, Nianzu. (2010). Hongqiao International Airport operation information system. Shanghai: Shanghai Scientific \& Technical Publishers, (Chapter 1).

Xiong, Honglin, Fan, Chongjun, Liu, Wujun, \& Zhang, Haiying. (2010). Research and design of passenger security information system based on two airports in a city mode. Computer Systems \& Applications, 19(4), 9-13.

Xiong, Honglin, Fan, Chongjun, Zhu, Xiaodong, Shu, Wenchun, Zhang, Zhuojian, \& Ji, Qingzheng. (2010). Research and Design on Passengers Traffic Information Services Mode of Hongqiao Transport Hub. International Journal of Business and Management, 5(4), 194-199.

Zhang, Lanying, Fan, Chongjun, Zhu, Xiaodong, Yang, Jianzheng, Shu, Wenchun, \& Zeng, Chen. (2010). Research and Design of Hongqiao Airport Water Management Information System. Computer and Information Science, 2(2), 86-93.

Zhang, Peng, Fan, Chongjun, Xu, Qinlan, Ran, Xianglai, Yu, Lu, Fang, Ding, \& Zhang, Zhuojian. (2011). 
Applications of Business Intelligence Technology in the Airports and Airlines Companies. International Journal of Applied Science and Technology, 1(5), 74-78.

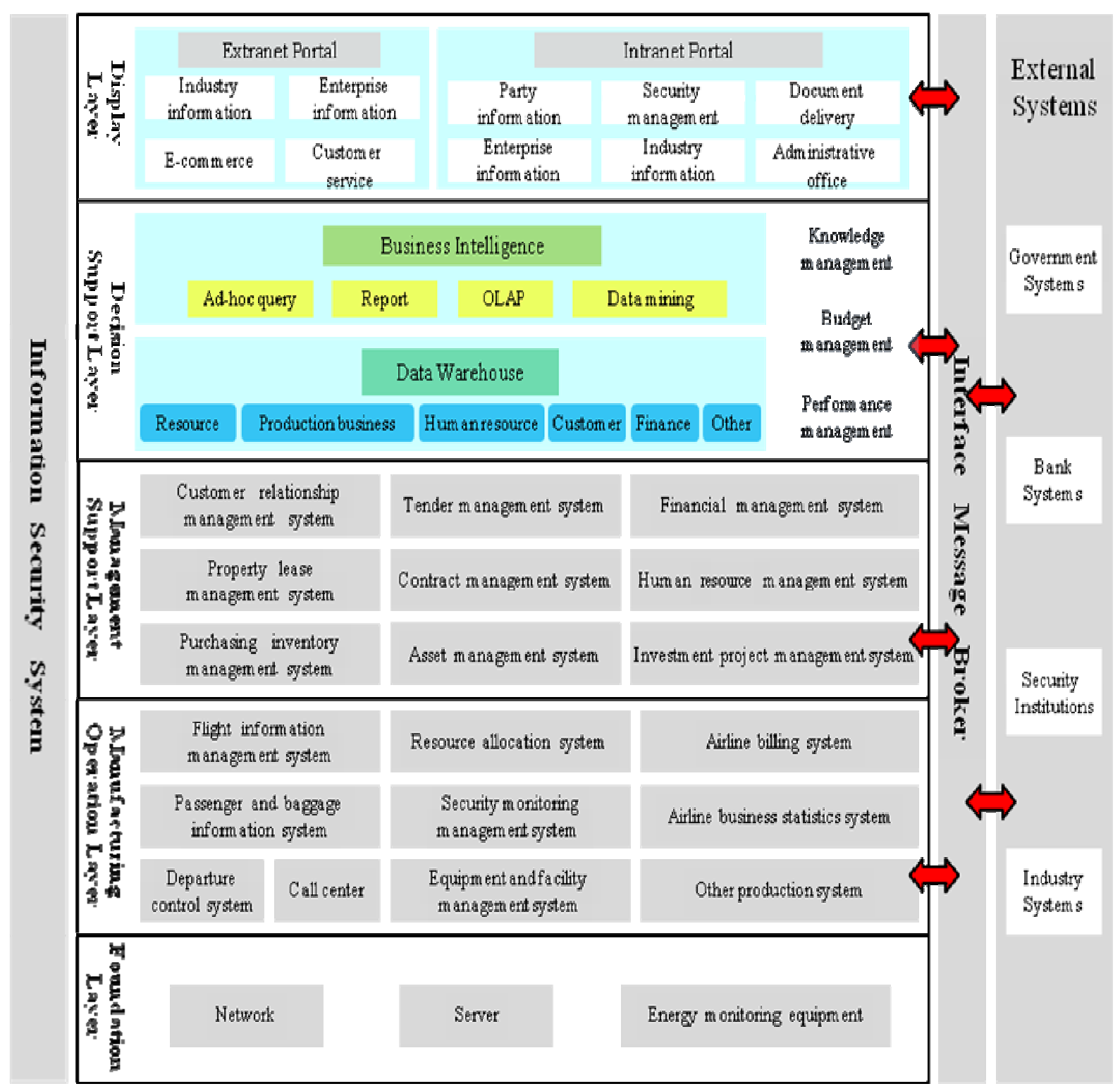

Figure 1. Application Blueprint of Shanghai Airport Business Intelligence System 


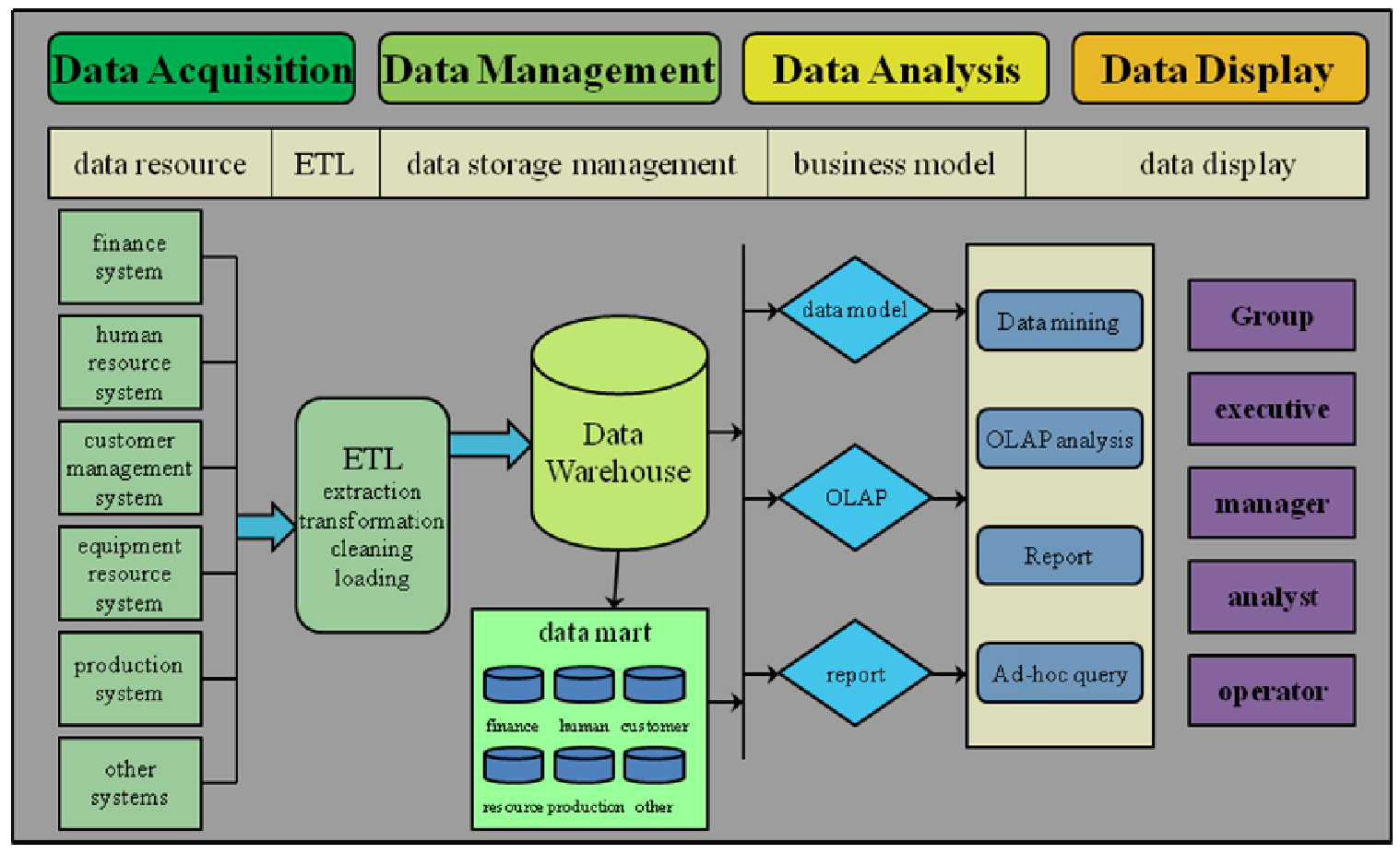

Figure 2. Technical Architecture of Shanghai Airport Business Intelligence System

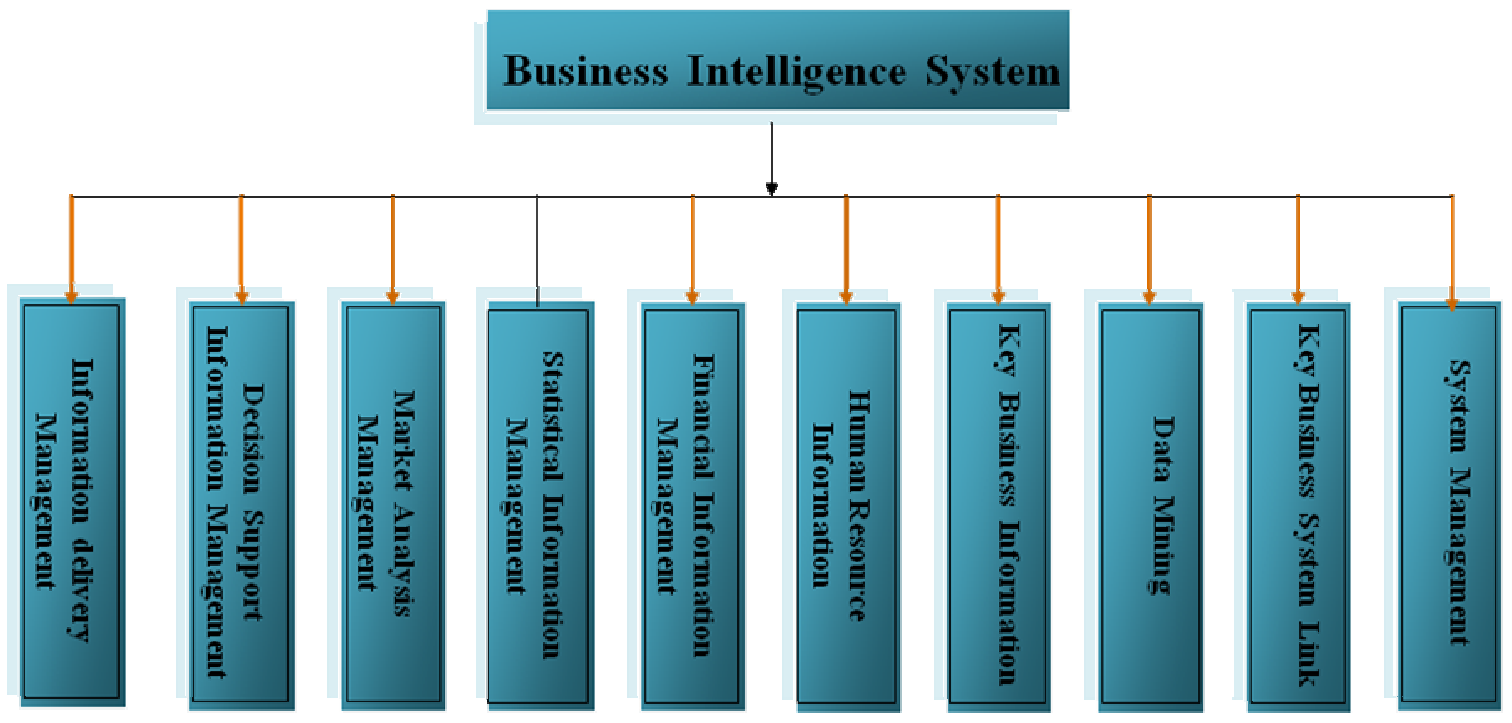

Figure 3. Application Architecture of Shanghai Airport Business Intelligence System 